\title{
Morbidity and mortality in motor neuron disease: comparison with multiple sclerosis and Parkinson's disease: age and sex specific rates and cohort analyses
}

\author{
TING-MING LI,* MICHAEL SWASH,† EVA ALBERMAN* \\ From the Department of Clinical Epidemiology, ${ }^{*}$ The London Hospital Medical College and Department of \\ Neurology, The London Hospital, $\uparrow$ London UK
}

SUMMARY The cause of motor neuron disease (MND) remains unknown although recent reports have suggested a possible rise in mortality rate. The present account describes age-specific patterns in morbidity rate and cross-sectional and cohort analyses of mortality rate, and compares these with those in multiple sclerosis and Parkinson's disease. First hospital admission rate for motor neuron disease (a proxy for incidence rates) rose steadily with age in males and females until the age of 75 years or more, but then fell, but only in females. This irregular pattern suggested the possibility of an environmental effect on certain older birth cohorts. The validity of the results was supported by a similar pattern in the two hospital regional authorities studied and the difference between this pattern and that found in multiple sclerosis and Parkinson's disease. Age-specific mortality rates of motor neuron disease between 15 and 64 years for males and females in England and Wales from 1940 to 1982 rose steadily with age. Mortality rates after the age of 65 fell in all female cohorts studied, but only in the earlier male cohorts. Unlike Parkinson's disease there was no strong birth cohort effect. However an analysis of Office of Population Censuses and Surveys (Registrar General) reports has revealed a slight increase in the agespecific mortality rate in both males and females aged 65 and over for successive birth cohorts? born since 1900 . Neither changes in ICD coding or in diagnostic habits could account for this pattern, which differed from that seen in Parkinson's disease. No such effect was seen in multiple sclerosis.

According to published reports the frequency of motor neuron disease seems to be fairly uniform throughout most of the world. ${ }^{2}$ Death rates from this disease within and between countries are for the most part between 1 and $1 \cdot 5$ per 100,000 population a year. Motor neuron disease is a disease of late middle life. In developed countries with comparatively elderly populations deaths from motor neuron disease amount to approximately $0.1 \%$ of all adult deaths and the average annual incidence rates for motor neuron disease are about 1 to $1 \cdot 5$ per 100,000 population. The duration of the disease after diagnosis is generally $2-5$ years, ${ }^{3}$ and in such countries

Address for reprint requests: Prof Eva Alberman, Dept of Clinical Epidemiology, The London Hospital Medical College, London E1 1BB, UK.

Received 12 June 1984 and in revised form 27 August 1984. Accepted 1 September 1984 prevalence rates of $2-6$ cases per 100,000 population have been reported. ${ }^{2}$ However, small areas of increased prevalence, such as Guam (a small island in the Pacific Ocean) and the Kii Peninsula of Japan have been described. In these areas a disease resembling motor neuron disease but accompanied by Parkinsonism and dementia is as much as $\mathbf{1 0 0}$ times more common than reported elsewhere. There is ar consistent reported male to female excess of 1.5 to 1 . In the USA the ratio of cases in whites and blacks is about $1 \cdot 5: 1^{\prime}$ but there is no other published information suggesting racial predisposition. Aside from age and sex, uniformly accepted risk factors for motor neuron disease have not been defined. Despite the apparent simplicity of the pathological process the cause or causes of the disease remain unknown. ${ }^{3-6}$

In Britain it is common practice for new cases to be admitted to hospital at least once for a full inves- 
tigation, so that first hospital admission with this diagnosis may be used as a proxy measure of incidence rates. In this paper we describe the pattern of first hospital admission for motor neuron disease and compare it with multiple sclerosis and Parkinson's disease. The mortality of these diseases in cohorts of different birth years have been compared in an attempt to generate new aetiological hypotheses.

\section{Methods}

In this paper, motor neuron disease is defined as a generic entity in accordance with the World Health Organisation (WHO) ICD code as used in the United Kingdom, in hospital statistical reports and mortality data.

\section{Hospital admission}

For the purpose of the present account first hospital admissions with ICD diagnoses of motor neuron disease, multiple sclerosis and Parkinson's disease (either as underlying or contributory cause) have been used as a proxy for crude incidence rates. The ICD codes used for motor neuron disease were ICD 348 for 1977 to 1978 and ICD 335.2 for 1979 to 1982 . For multiple sclerosis this was ICD 340 for 1977 to 1982 and for Parkinson's disease they were ICD 342 for 1977 to 1978 and ICD 332.0 or 332.1 for 1979 to 1982. First admission rates of residents in the North East Thames and Oxford Regional Health Authority for the years 1977 to 1982 were calculated from data supplied by the Regional Health Authorities based on Hospital Activity Analysis, and classified by age and sex. The corresponding regional population figures from OPCS were used to estimate age and sex-specific rates.

For each year and sex, the number of patients first admitted to a hospital within the two regions studied per 100,000 population (adjusted to the 1979 to 1982 population of Oxford and NE Thames) was calculated. For the Oxford Region record linkage makes it possible to distinguish between first admission and readmission for the same disease; ${ }^{7}$ for NE Thames listings of admission with the relevant diagnoses were ordered by patients' date of birth as well as by hospital record number, and then matched by hand according to sex, hospital number and district of residence; names and addresses are not given for reasons of confidentiality. It was thought that the resultant admissions were largely first admissions and the close correspondence with the Oxford data shown below suggest that this was the fact.

\section{Cohort analysis}

Mortality statistics published by Office of Populanons Censures and Surveys for the years 1940 to 1982 were the source of cohort analyses reported below. Mortality rates for birth cohorts with diagnoses of motor neuron disease, multiple sclerosis and Parkinson's disease were assembled. There have been several changes in the codes for ICD these conditions over this time. Before 1940 it was not possible to distinguish clearly between motor neuron disease and other diagnoses. For motor neuron disease the codes were: ICD 82(1) for 1940 to 1949; ICD 356 for
1950 to 1967 ; ICD 348 for 1968 to 1978 ; and ICD $335 \cdot 2$ for 1979 to 1982 . For multiple sclerosis these were: ICD 87(d) for 1940 to 1949 ; ICD 345 for 1950 to 1967 ; ICD 340 for 1968 to 1982. For Parkinson's disease they were: ICD 87(c) for 1940 to 1949 ; ICD 350 for 1950 to 1967 ; ICD 342 for 1968 to 1978 ; ICD 322.0 or 322.1 for 1979 to 1982.

Birth cohort mortality rates by age and sex for England and Wales for the years 1940 to 1982 were calculated from these data and the corresponding population figures from Office of Populations Censures and Surveys were used to estimate age and sex-specific rates.

The data are the averages of the successive quinquennia: 1940-44, 1945-49, etc, except for 1980-82 which is the average of these three years.

\section{Results}

Hospital activity analysis: Age-specific rates in each region.

The number of patients admitted per 100,000 population in each of the two Regional Health Authorities from 1977 to 1982 were calculated for each year. Age-specific first admission rates for motor neuron disease, multiple sclerosis and Parkinson's disease in the Oxford and NE Thames Regions are given in fig 1 .

The age-specific rates for motor neuron disease in both regions indicate a peak at 70 to 79 years for women and then a drop. Figure 2 shows that in men the age-specific rates continued to increase even in

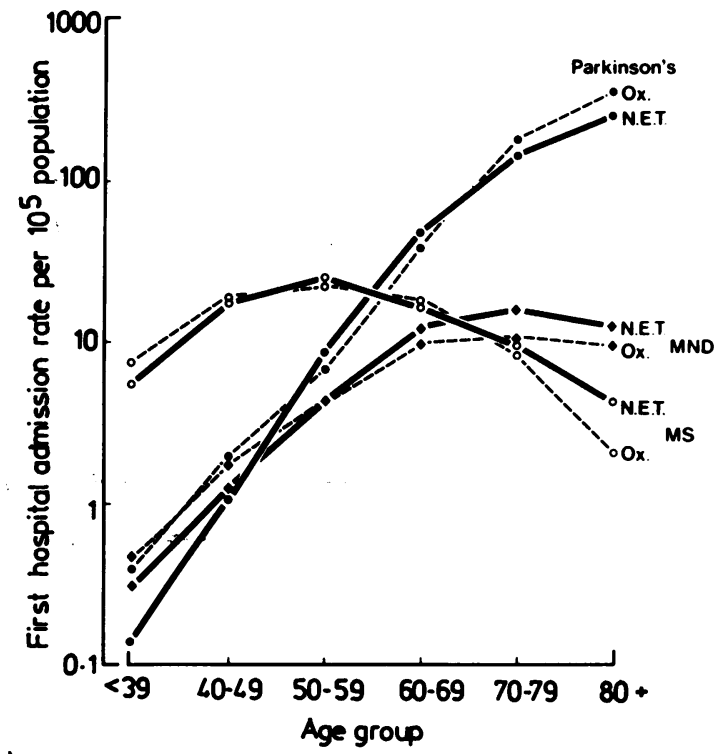

Fig 1 First hospital admission rates for disease specified NE Thames and Oxford RHAs: 1977-1982. 
(a)
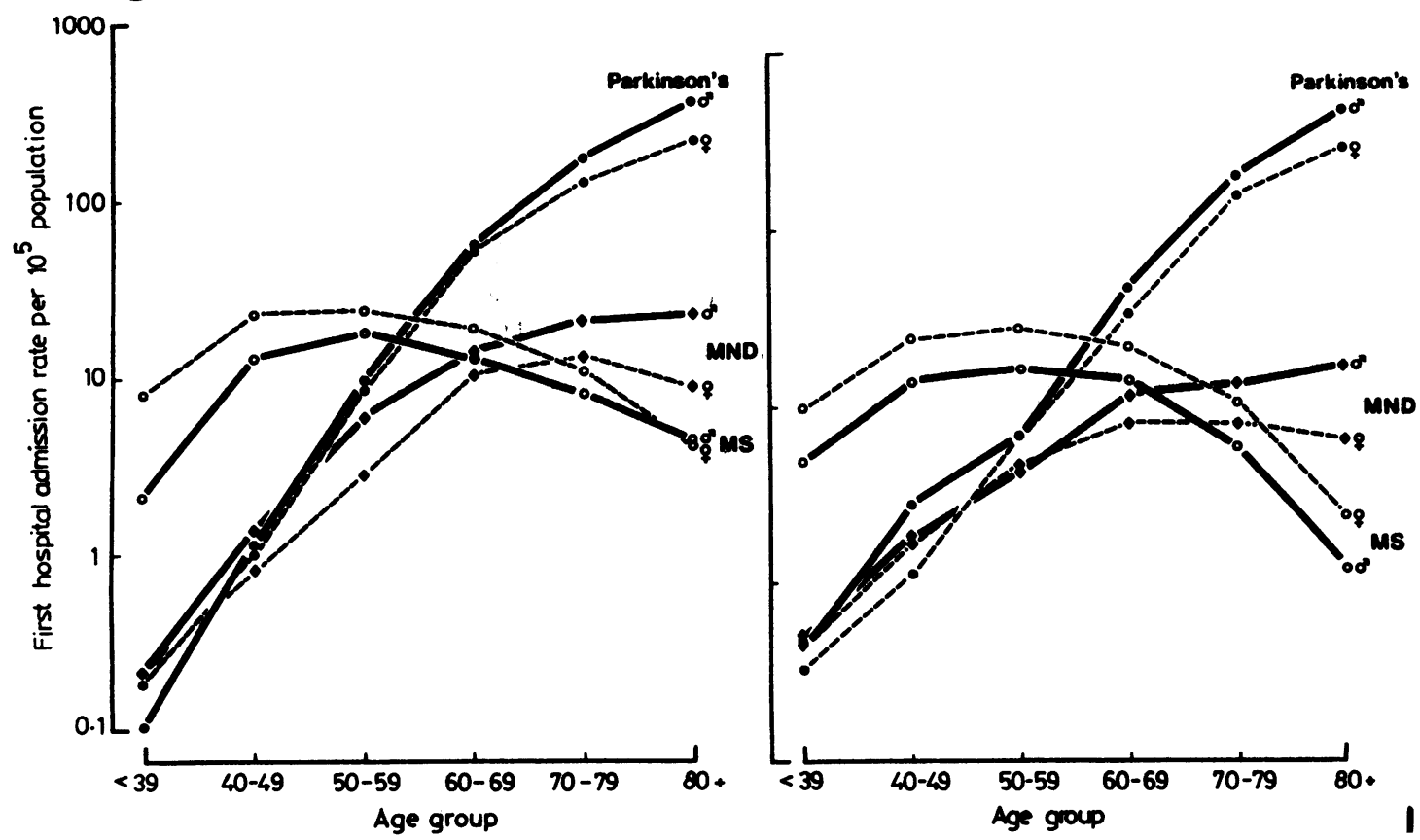

Fig 2 First hospital admission rate by sex for disease specified (a) NE Thames RHA; (b) Oxford RHA: 1977-1982.

the age group of 80 or more but in women the rate in this age group falls. Although the age specific rates in the Oxford RHA are lower than in NE Thames, the patterns were the same. The patterns for multiple sclerosis and Parkinson's disease are clearly different from that for motor neuron disease, and from each other, with a peak in the age group 50 to 59 for multiple sclerosis and then a sharp fall, but a continuing rise with age in Parkinson's disease (fig 2) in both sexes.

The crude first hospital admission rate (all ages) of multiple sclerosis was about 2.8 times that of motor neuron disease and of Parkinson's disease about 6.6 times that of motor neuron disease.

\section{Sex ratio}

The sex ratio and changes in sex ratio at differen ages in the Oxford region are given in fig 2 and the table. The findings were very similar to those from NE Thames where there were 432 male cases and 355 female cases of motor neuron disease, giving an overall sex ratio of $1 \cdot 22: 1$. There were 790 male cases and 1435 female cases of multiple sclerosis, giving an overall sex ratio of $1: 1 \cdot 82$, and there were 2388 male cases and 2829 female cases of Parkinson's disease, giving an overall sex ratio of $1: 1 \cdot 18$.

Birth cohort mortality analyses

Birth cohort specific mortality rates, on a log scale,

Table Sex ratio at different ages for motor neuron disease, multiple sclerosis and Parkinson's disease: 1977-1982 in Oxford RHA

\begin{tabular}{|c|c|c|c|c|c|c|c|c|}
\hline & & Under 39 & $40-49 y r$ & $50-59 \mathrm{yr}$ & $60-69 \mathrm{yr}$ & $70-79 y r$ & Over $80 y r$ & Total \\
\hline Motor neuron disease & $\begin{array}{l}\text { No of male cases } \\
\text { No of female cases } \\
\text { Sex ratio }\end{array}$ & $\begin{array}{l}18 \\
17 \\
1 \cdot 06: 1\end{array}$ & $\begin{array}{l}13 \\
12 \\
1.08: 1\end{array}$ & $\begin{array}{c}28 \\
31 \\
1: 1 \cdot 11\end{array}$ & $\begin{array}{c}61 \\
47 \\
1 \cdot 30: 1\end{array}$ & $\begin{array}{l}42 \\
35 \\
1 \cdot 20: 1\end{array}$ & $\begin{array}{r}14 \\
14 \\
1: 1\end{array}$ & $\begin{array}{c}176 \\
156 \\
1 \cdot 13: 1\end{array}$ \\
\hline Multiple sclerosis & $\begin{array}{l}\text { No of male cases } \\
\text { No of female cases }\end{array}$ & $\begin{array}{l}183 \\
359 \\
1.1 .96\end{array}$ & $\begin{array}{l}99 \\
173 \\
1.1 .75\end{array}$ & $\begin{array}{l}110 \\
188 \\
1.1 .71\end{array}$ & $\begin{array}{l}74 \\
117 \\
1.1 .58\end{array}$ & $\begin{array}{l}18 \\
43 \\
1 \cdot 2 \cdot 39\end{array}$ & $\begin{array}{c}1 \\
5 \\
1.50\end{array}$ & $\begin{array}{c}485 \\
885 \\
1.1 .82\end{array}$ \\
\hline Parkinson's disease & $\begin{array}{l}\text { No of male cases } \\
\text { No of female cases } \\
\text { Sex ratio }\end{array}$ & $\begin{array}{l}1: 1.90 \\
17 \\
12 \\
1 \cdot 42: 1\end{array}$ & $\begin{array}{c}1: 1.13 \\
20 \\
8 \\
2 \cdot 50: 1\end{array}$ & $\begin{array}{l}1: 1 \cdot 11 \\
46 \\
45 \\
1 \cdot 02: 1\end{array}$ & $\begin{array}{l}1.1 \cdot 38 \\
242 \\
190 \\
1 \cdot 26: 1\end{array}$ & $\begin{array}{l}1: 2 \cdot 39 \\
617 \\
664 \\
1: 1 \cdot 08\end{array}$ & $\begin{array}{l}1: 30 \\
400 \\
605 \\
1: 1 \cdot 51\end{array}$ & $\begin{array}{l}1.1 \cdot 02 \\
1342 \\
1524 \\
1: 1 \cdot 14\end{array}$ \\
\hline
\end{tabular}


(a)
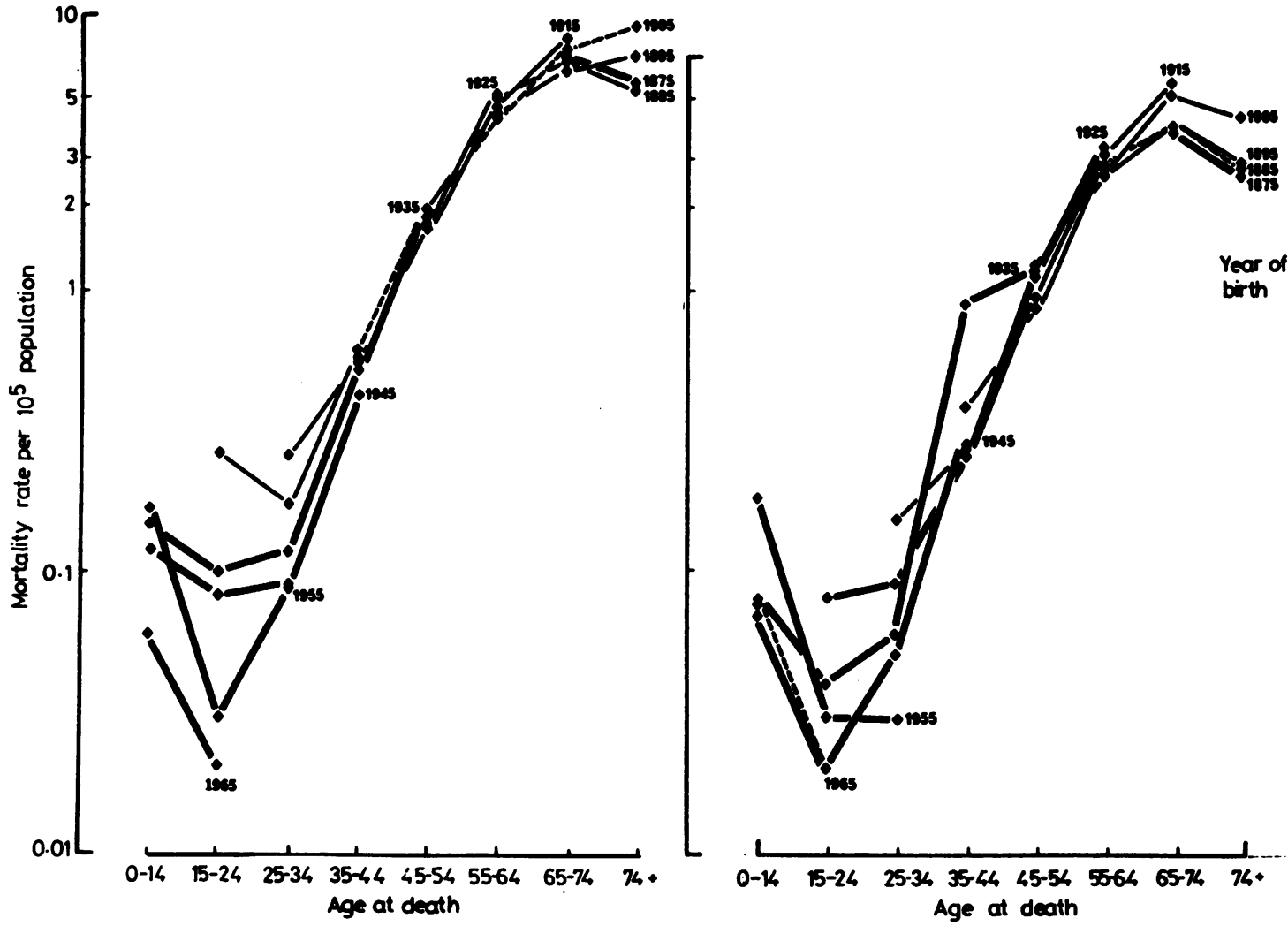

Fig 3 Age at death, sex, and birth cohort specific mortality rates for motor neuron disease in England and Wales between 1940 and 1982. The rates are expressed as the average of decennial rates to cohorts born between 1875 and 1884; 1885 and 1894 etc. The date given on curve is the first year of the decennium of birth (a) males (b) females.

of males and females for motor neuron disease, multiple sclerosis and Parkinson's disease presented so as to show differences between birth cohorts at varying ages are given in figs 3,4 and 5 .

Age-specific mortality rates of males and females for motor neuron disease, multiple sclerosis and Parkinson's disease presented so as to show changes for different years of birth within the same agegroup are given in figs 6,7 and 8 .

\section{Discussion}

\section{Morbidity data}

Before considering the results of these analyses the validity of using first hospital admission for motor neuron disease as a proxy for incidence data must be discussed. Amongst the problems this poses are the incomplete nature of Hospital Activity Analysis, for it is known that several hospitals in both Regions did not contribute to Hospital Activity Analysis until the later part of the study period. Furthermore not all patients with motor neuron disease are admitted to hospital. Although, in our judgement, the majority of recognised cases are admitted at least once for investigation, there will certainly be some cases, particularly those that first occur in extreme old age that, even if they are recognised as motor neuron disease, may not be admitted. There is also the problem that patients may be admitted for the first time at different stages of the disease, from very early to very late in its history. Finally there will certainly be cases, admitted to hospital or not, which are never correctly diagnosed and will therefore not appear in this diagnostic category.

A different problem is the question of movement between regions. The analysis of the Hospital Activity Analysis data are based only on residents in the respective Regions, and exclude patients from out- 

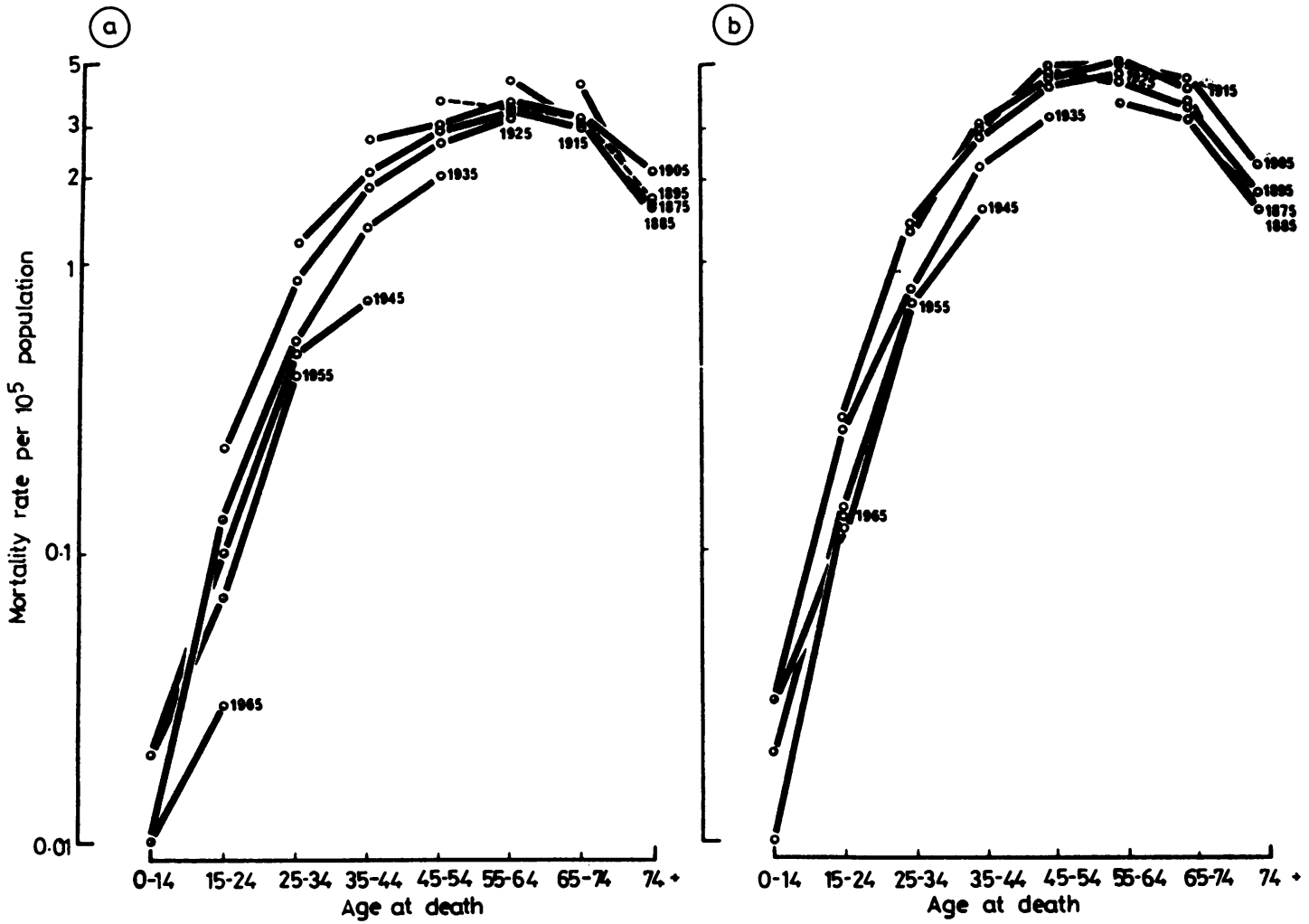

Fig 4 Age at death, sex, and birth cohort specific mortality rates for multiple sclerosis in England and Wales between 1940 을 and 1982. The rates are expressed as the average of decennial rates to cohorts born between 1875 and $1884 ; 1885$ and $\risingdotseq$ 1894 etc. The date given on curve is the first year of the decennium of birth (a) males (b) females.

side coming into the two Regions studied for treatment or diagnosis. This could lead to a systematic loss of data for admissions outside Region of residence. We think that this is unlikely to happen often in the case of residents of the North East Thames Region, which includes the Institute of Neurology, and has working within its boundaries approximately half of the neurologists in the country. Neurological expertise in the Oxford Region is also of a high order and again there is unlikely to be a substantial flow out of the Region for hospital care.

For all these reasons however the first admission rate is likely to be an underestimate, rather than an overestimate of the incidence. However the strong similarity between the data for the two regions we have studied suggests that the data are reliable enough for a study of the presenting patterns of the diseases studied. Moreover the data conform closely to what is already known about the diseases from other sources.
Comparing the patterns of motor neuron disease with the patterns of multiple sclerosis and Parkinson's disease (figs 1 and 2), it is very clear that the patterns of the three diseases are different as regards sex ratio and the peak of the age specific rates of first admission. Age-specific rates for motor meuron disease in both the Oxford and NE Thames Regional Health Authorities indicate a peak at age 70 to $79 \div$ and then a fall for females but rise continuously for males up to 80 or more (fig 2). Parkinson's disease shows a different pattern with a continuing rise with age for both sexes (fig 2). We are not aware of previous estimates of age-specific incidence rates for 윽 motor neuron disease; previous reports only quote $>$ frequency distributions. It is therefore worth drawing attention to the fact that incidence rates in males $N$ steadily increase with age, although there is a fall in the oldest female age group. The irregular pattern $N$ shown for motor neuron disease suggest the possibil- $\mathbb{N}$ ity of a small change in risk for different cohorts. 
(a)

(b)
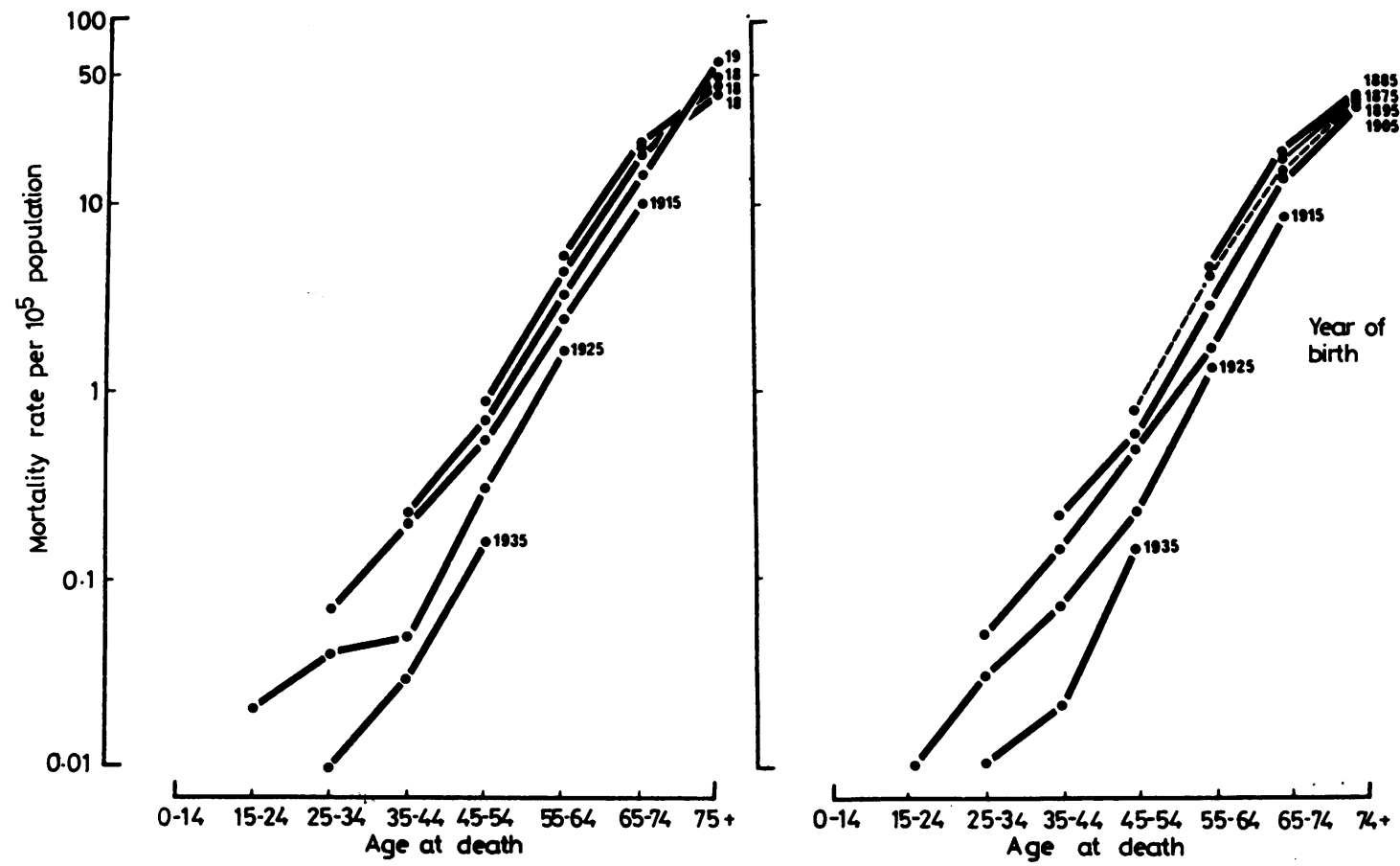

Fig 5 Age at death, sex, and birth cohort specific mortality rates for Parkinson's disease in England and Wales between 1940 and 1982. The rates are expressed as the average of decennial rates to cohorts born between 1875 and 1884; 1885 and 1894 etc. The date given on curve is the first year of the decennium of birth (a) males (b) females.

(a)

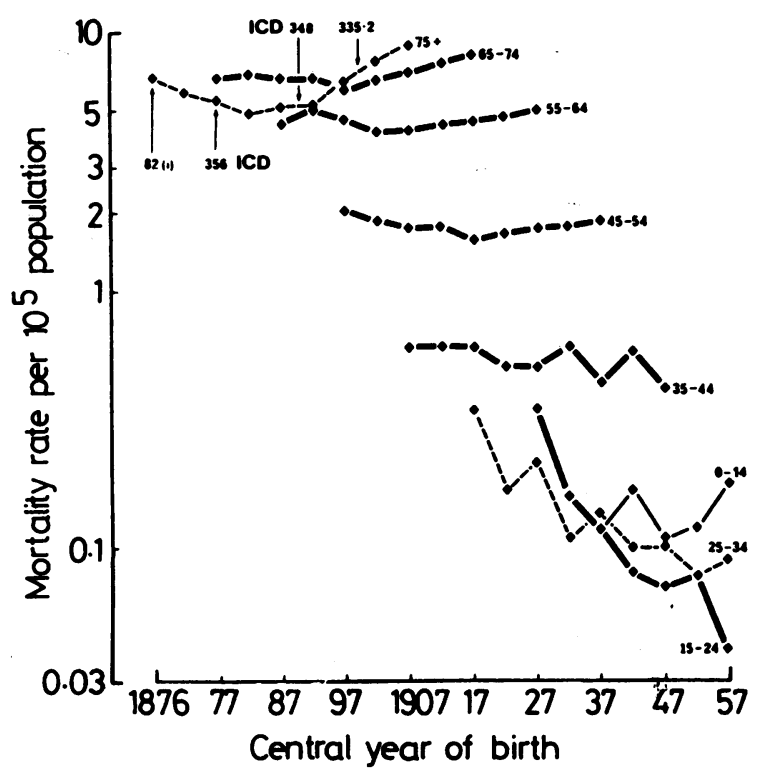

(b)

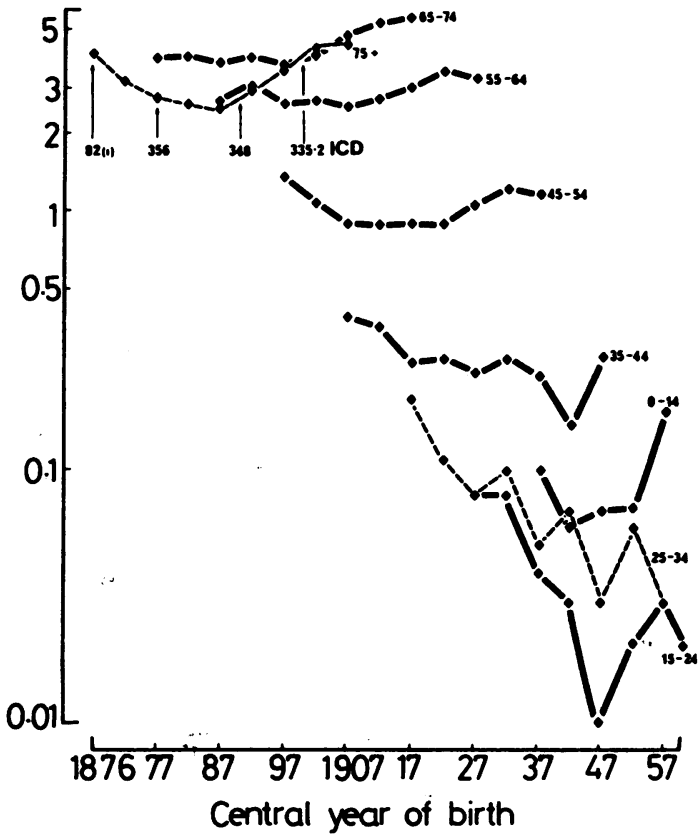

Fig. 6 Trends in age and sex specific mortality rates for motor neuron disease. The data refer to deaths in England and Wales between 1940 and 1982, and the years on the abscissa represent the central year of the decennium of birth (a) males (b) females. 
(a)

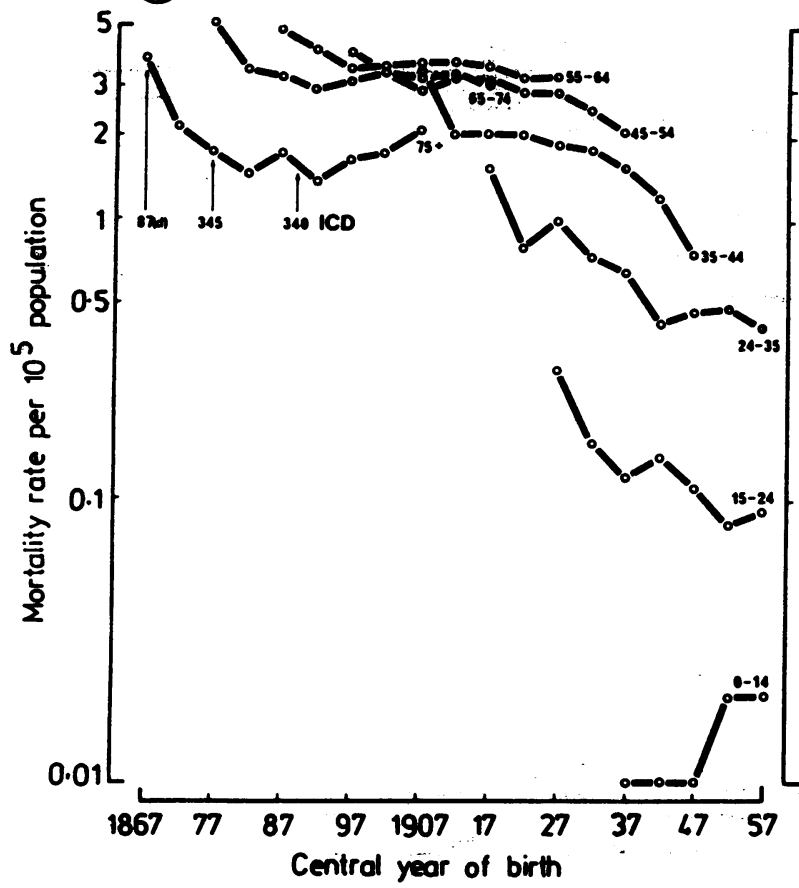

(b)

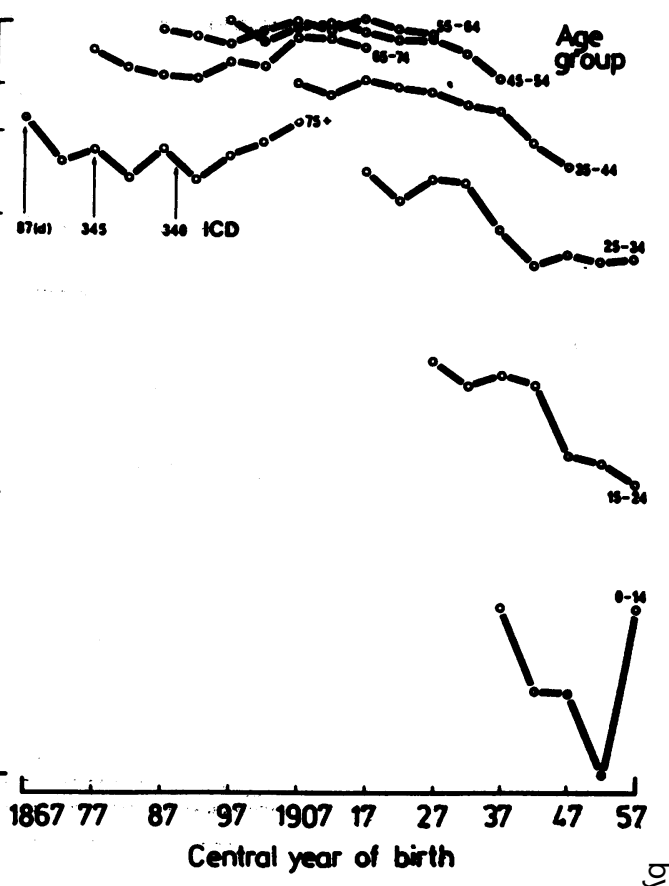

Fig 7 Trends in age and sex specific mortality rates for multiple sclerosis. The data refer to deaths in England and Wales between 1940 and 1982, and the years on the abscissa represent the central year of the decennium of birth (a) males (b) females.

(a)

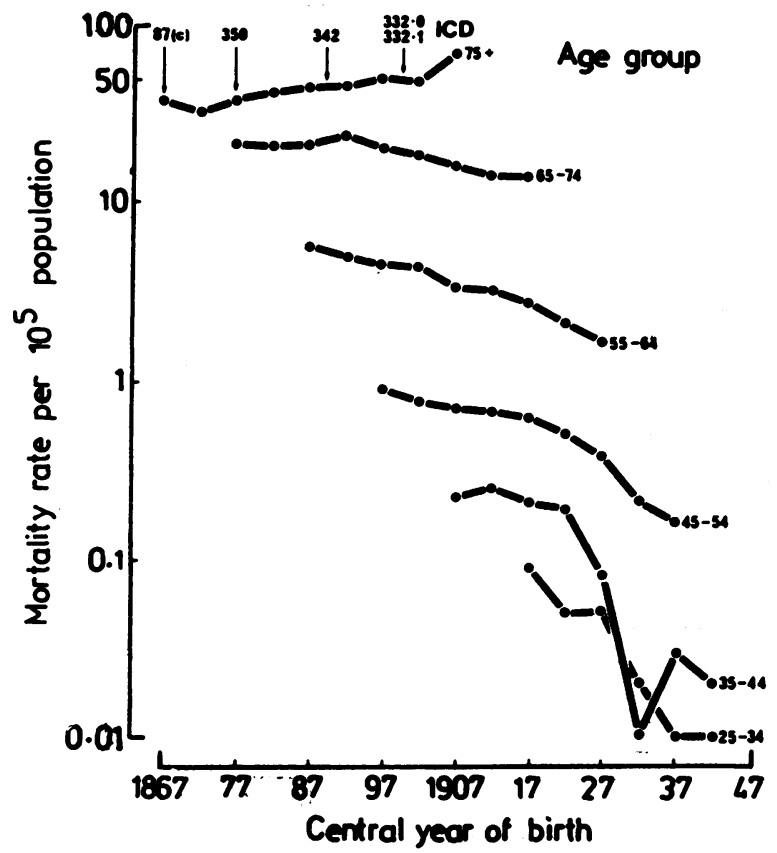

(b)

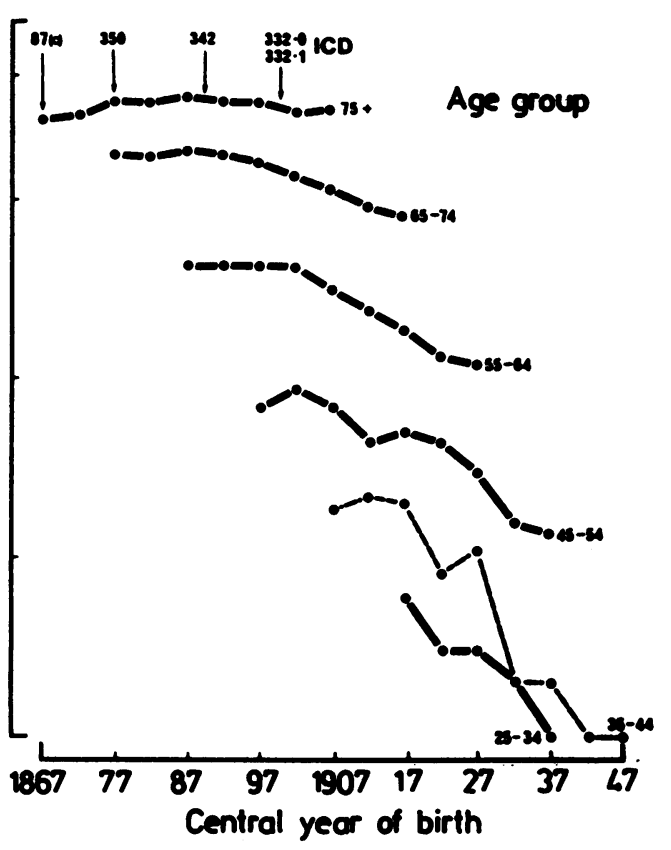

Fig 8 Trends in age and sex specific mortality rates for Parkinson's disease. The data refer to deaths in England and Wales? between 1940 and 1982, and the years on the abscissa represent the central year of the decennium of birth (a) males (b) females. 


\section{Mortality data}

Buckley and colleagues ${ }^{\curlyvee}$ and Holloway and colleagues ${ }^{9}$ have suggested from cross-sectional mortality data that the age specific mortality rates for motor neuron disease may be increasing, the former described trends for England and Wales from 1959 to 1979 , and the latter for Scotland from 1.968 to 1977. We do not know how much of the increase can be attributed to improved standards of diagnosis and death certification and how much, if at all, it reflects a real increase in incidence of motor neuron disease. However, changing trends in disease rates may provide valuable clues to aetiology when compared with trends in environmental influences including those affecting life style within the community under consideration. Such an effect, with falling rates in more recent cohorts, is clearly seen in Parkinson's disease (fig 8) and has been previously reported by Marmot. ${ }^{10}$ Figure 3 shows that for males in the birth cohort 1905 age specific mortality rates of motor neuron disease may indeed be higher than in later cohorts, while in females the same effect is seen in earlier birth cohorts. These changes are less marked than those found in Parkinson's disease (fig 5) and they are not seen at all in multiple sclerosis (fig 4). Together with the hospital data they raise the possibility that for males the birth cohort of 1905 might have been at slightly higher risk of motor neuron disease than earlier and later cohorts, while the same may be true for the cohort of females born in 1915 (fig 3).

The fact that these trends do not correspond with changes in ICD coding (figs $6,7,8$ ) and are different in males and females (fig 6) suggests that they are unlikely to be artefacts of coding or different diagnostic practices over the years. There are no obvious explanations for the observed trend and sex differences, but there may be an environmental factor or factors to which the cohorts were exposed in earlier life, and it is possible that males and females are vulnerable at different ages.

Dr MJ Goldacre and Dr GA Ellam kindly made available the Oxford Hospital Activity Analysis data, and Mr Brian Russell supplied the NE Thames Regional Health Authority data. We also thank $\mathrm{Mr}$ Stephen Evans and Dr Alan Silman, The London Hospital Medical College for their help and advice.

\section{References}

' Kurtzke JF. Epidemiology of amyotrophic lateral sclerosis. In: Rowland LP, ed. Advances in Neurology 1982;36:281-302.

2 Jokalainen M. Amyotrophic Lateral Sclerosis in Finland. An Epidemiologic Study. Acta Neurol Scand 1977;56: 185-93.

${ }^{3}$ Kondo K. Motor Neuron Disease: changing population patterns and clues for aetiology. Advances in Neurology 1978;19:509-43.

${ }^{4}$ Mulder DW, Rosenbaum RA, Layton DD. Late Progressive for poliomyelitis or form fruste amyotrophic lateral sclerosis? Mayo Clin Proc 1972;47:756.

${ }^{5}$ Conradi S, Ronnevi LO, Vesterber O. Abnormal tisue distribution of lead in amyotrophic lateral sclerosis. $J$ Neurol Sci 1976;29:259-65.

- Kondo K, Tsubaki I. Case-control studies of motor neuron disease association with mechanical injuries. Arch Neurol 1981;38:220-6.

' Acheson ED. Medical Record Linkage. London: Oxford University Press for the Nuffield Provincial Hospital Trust. 1967.

${ }^{\star}$ Buckley J, Warlow C, Smith P, Hilton-Jones D, Irvine S, Tew JR. Motor neuron disease in England and Wales, 1959-1979. J Neurol Neurosurg Psychiatry 1983;46:197-205.

${ }^{9}$ Holloway SM, Emery AEH. The epidemiology of motor neuron disease in Scotland. Muscles Nerve 1982:131-3.

${ }^{10}$ Marmot MG. Mortality and Parkinson's disease. In: Clifford Rose, ed. Research Progress in Parkinson's disease 1981:9-16. 